\title{
EL PROYECTO ARQUEOLÓGICO DE FOUCAULT Y EL GOBIERNO POR LA VERDAD JURÍDICA. LA SEDE DEL MÉTODO ARQUEOLÓGICO EN LOS UMBRALES DEL CAMPO DISCURSIVO
}

\section{THE FOUCAULT'S ARCHAEOLOGICAL PROJECT AND THE GOVERNMENT BY LEGAL TRUTH. THE LOCATION OF THE ARCHAEOLOGICAL METHOD IN THE THRESHOLDS OF THE DISCURSIVE FIELD}

\section{Paulo Damián Aniceto*}

\section{RESUMEN}

En este ensayo, ofrecemos una revisión de las posturas críticas del proyecto arqueológico foucaultiano. Nos prestamos, en una primera instancia, a recoger aspectos que creemos centrales de su preocupación por el acontecimiento de la práctica discursiva y sugerimos modestas derivas interpretativas que ponen los aportes post estructuralistas sobre al saber y el poder al servicio del análisis crítico del discurso jurídico. En una segunda instancia, describimos brevemente el carácter positivo de la práctica discursiva en ámbitos prescriptivos y ofrecemos un marco teórico capaz de adecuar la teoría de las formaciones discursivas a los campos discursivos que no construyen sujetos sino a en contextos de confrontación y disputa. Nuestra propuesta, en definitiva, pretende ser una contribución a extraer las consecuencias de considerar los campos y espacios discursivos como gramáticas que normalizan jurídicamente el discurso emergente pero que no anulan, por esto, su carácter contingente.

Palabras clave: La arqueología del saber; Foucault; discurso jurídico; campo discursivo agonístico; origen y regularidad.

\section{ABSTRACT}

In this essay, we offer a review of the critical positions of the Foucaultian archaeological project. We propose, in a first instance, to pick up aspects that we believe are central to his concern for the event of discursive practice and we suggest modest interpretive drifts that put post structuralist contributions on knowledge and power at the service of critical analysis of legal discourse. In a second instance, we briefly describe the positive nature of discursive practice in prescriptive fields and offer a theoretical framework capable of adapting the theory of discursive formations to the discursive fields that do not construct subjects but in contexts of confrontation and dispute. Our proposal, in short, pretends to be

\footnotetext{
* Universidad Nacional de Córdoba, Córdoba, Argentina. paulodamiananiceto@gmail.com.
} 
a contribution to extract the consequences of considering the fields and discursive spaces like grammars that normalize juridically the emergent discourse but that do not annul, by this, its contingent character.

Keywords: The Archaeology of Knowledge; Foucault; legal discourse; agonistic discursive field; Origin and regularity.

La historia ya no conserva la función totalizadora que consistía en sustituir a la filosofía en el oficio de indicar el sentido de las cosas (DE CERTEAU, 1978, p. 94).

Sería injusto desconocer los aportes del proyecto arqueológico foucaultiano a la discusión sobre las relaciones que los discursos, dispositivos, mantienen con dimensiones cuya definición se encuentra aún hoy en pugna: la verdad y las instituciones, el sentido y la contingencia, el origen y el sujeto, la coacción y la libertad, etc. Asimismo, el repertorio de voces críticas que emergieron al encuentro de lo que entendían como "lagunas metodológicas" e "infracciones epistemológicas" del planteamiento, compone un espectro no desdeñable.

Uno de los puntos principales de las críticas realizadas al método arqueológico, sin duda, es ocupado por las observaciones sobre la ambivalencia de la posición construida por Foucault para el arqueólogo, abocado, como lo anuncia La arqueología del saber desde sus primeras páginas, a "la descripción intrínseca del monumento" (FOUCAULT, 1969, p. 17).

Creemos necesario interpretar nuevamente el lugar asignado por nuestro autor a su producción pre-metodológica, poniendo a prueba la capacidad relacional de sus categorías. Ensayamos un paso en esa dirección, al distinguir la identidad de su propuesta teórica de la del dominio estructuralista y al preguntarnos por la fecundidad de su obra en el campo del análisis del discurso del presente. Concluimos en una reflexión que sugiere los aportes que el planteamiento arqueológico puede realizar al abordaje de campos discursivos en distintos espacios de discurso social.

\section{EL PUNTO DE PARTIDA DE LAS ESTRUCTURAS}

\subsection{La descripción intrínseca}

"Analizando los propios discursos se ve cómo se afloja el lazo al parecer tan fuerte de las palabras y de las cosas", considera Foucault (1969, p. 68). Sería prudente una revisión detenida del glosario que toma forma en La ardueología del saber 
antes de apresurarnos a concluir sobre el matiz estructuralista del conjunto de su propuesta. Durante una de sus entrevistas, su interlocutor aseguraba: "con diversa fortuna, ha tratado usted de desprenderse del membrete del estructuralismo" (en FOUCAULT, 1969, p. 237). En el desarrollo del proyecto arqueológico, la opción por el estudio del monumento da cuenta de su interés en la noción de bistoria general (HGr) y supone un estado de crisis de las seguridades que la noción de bistoria global $(H G)^{1}$ aportaba a la historia de las ideas.

En síntesis, el documento, la imagen de una voz que, autorizada por la tradición, restituye y resguarda un sistema de reglas, es reemplazado por la imagen de otra voz que emerge en medio de tensiones entre lo dicho y lo por decir. El abordaje arqueológico del discurso-monumento se propone describir las reglas de la unidad de un dominio para revelar la discontinuidad de las series que lo componen. Pero estas reglas difieren de aquellas que la tradición pone a la vista, al dar cuenta de las relaciones de sumisión de unos discursos excluidos o separados a otros discursos excluyentes y autorizados. Es decir, el concepto de discurso-dispositivo consiste, en un primer orden, en recomponer la evidencia de las relaciones de poder como el medio ambiente de las prácticas discursivas y, en segundo orden, desentrañar la agencia de la lingüística estructural y la gramática de Port Royal en el ocultamiento de esa evidencia.

Por esta razón, el estatuto de lo intrínseco del monumento constituido en el objeto de la descripción, no debería ser confundido con el de lo intrínseco del documento. Un análisis de las condiciones históricas de aparición del discurso se debería ubicar, claro está, en el lugar en el que se produce el desplazamiento y el movimiento. Donde irrumpen nuevos objetos, nuevas concepciones en formas distintas de coexistencia dentro de campos enunciativos.

En el cuarto capítulo de Michel Foucault, más allá del estructuralismo y la bermenéutica, Dreyfus y Rabinow (1982) componen un robusto conjunto de críticas al andamio epistemológico foucaulteano. Los autores sostienen que está asentado sobre nociones que privilegian la figura de un analista neutro que guarda una distancia indeterminada e indeterminable con los discursos serios de sentido. A continuación,

1. Un eventual trabajo abocado a completar un glosario técnico del método arqueológico comenzaría, quizás, distinguiendo la noción de la $H G r$ como un eje rector del planteo foucaulteano. Diremos, sin pretender consumar ese trabajo en pocas líneas, que, a diferencia de la HGr, la HG no hace más que reproducir - repetir - los sistemas de separación y exclusión al interior de los cuales se forman los discursos. Foucault entiende que el discurso, limitado en disciplinas, serio de sentido, vehiculiza una voluntad de verdad y se esfuerza en probar la prevalencia de un núcleo de sentido que no haría más que restituirse a través suyo. 
emprendemos la tarea de descomposición y puesta a prueba de sus principales conclusiones.

\subsection{El arqueólogo y su distancia con el monumento}

Foucault (1966, 1970, 1969) admite que los discursos están formados por signos pero niega que su función sea corresponder a un referente. Para valorar la distancia que el autor toma de la ilusión referencial, volvemos sucintamente sobre el espacio que dedica a temas como el sujeto fundador, la verdad, origen/regularidad y el sentido.

La noción de sujeto fundador se encuentra implicada en la de actualización discursiva de un sentido original que permanecería previamente, silencioso pero vigente, en complicidad con el sujeto originario. La genealogía foucaultiana atribuye a esta perspectiva idealista dos efectos que, en relación con las prácticas discursivas, cumplirían una misma función. Por un lado, observa el desarrollo de la antropología que asume al sujeto empírico como portador de una especie de memoria de aquella experiencia primera transmitida por la tradición. Esta visión se sustenta en la ilusión de que el mundo nos devolvería, en términos de la crítica de Foucault, "una cara legible que no tendríamos más que descifrar" (FOUCAULT, 1969, p. 33). En otras palabras, la lectura del mundo como un referente explícito del discurso se constituye en lectura discreta.

\subsection{El sujeto fundador y el principio de limitación del autor}

El del sujeto fundador es, asegura Foucault, uno de los conceptos de la filosofía que operan reforzando los procedimientos de exclusión y control del dispositivo del discurso. Esta noción consagra la idea de un sujeto que, "del otro lado del tiempo, funda horizontes de significados" (Foucault, 1966, p. 48) a los que un análisis serio debería remitirse para descubrir el vínculo necesario entre los discursos y el significado que, bajo este punto de vista, fecundaría sus formas vacías.

Con esto, resulta comprensible su llamado de atención en unas de sus clases en el Collège de France: "se trata de anular cada vez uno de los términos de la relación y no de suprimir la relación misma" (FOUCAULT, 1966, p. 28). Podremos asir esta premisa si entendemos que Foucault persiste motivado por una inquietud de segundo orden: la de reconocer el dominio disciplinar de la lingüística y la historia moderna como aquel interesado en favorecer y poner en relación dos objetos: el horizonte de significado y el significante. Relación fundamental que produce el efecto de ficción en el que el segundo funciona como prueba de la supervivencia 
incontaminada del primero. Relación resuelta, estima Foucault, a favor de la figura del antropólogo, abocado desde siempre al resguardo del sujeto que ostenta el poder sobre el significante y que, por medio de él, mantiene su relación de complicidad primitiva con el mundo. Relación, en fin, establecida entre el sujeto en su dimensión psicológica y la verdad pasible de ser aprehendida. Relación, confirmaría el mismo Foucault (1966), que es necesario historizar para "replantearnos nuestra voluntad de verdad" (51).

\subsubsection{El gobierno del sujeto por la verdad}

El propósito de reformular conceptos como sujeto y mundo de la representación evoca la intersección disciplinar sobre la que Foucault asienta su trayecto intelectual cuando describe las relaciones de saber y poder que vinculan al sujeto con una verdad. Esa intersección es la producida entre el psicoanálisis y los programas de control jurídico del discurso. En las clases dictadas en Lovaina en 1981, Obrar mal, decir la verdad, el autor ofrece una genealogía de las prácticas de veridicción y jurisdicción, como problemas políticos y filosóficos que deben ser reconocidos para describir el ejercicio del gobierno por la verdad jurídica sobre el sujeto. El discurso jurídico compone uno de los espacios discursivos del campo discursivo social donde aparece más explícitamente la interpelación institucional a un sujeto que acepta vincularse a la verdad que se le atribuye ${ }^{2}$. El argumento judicial tenido por válido se encuentra reservado a unos pocos autorizados, que acaban por asumir la agencia de ocultamiento y clausura de las técnicas de manipulación social. Desentrañar el lugar reservado para el sujeto en el discurso jurídico puede devolvernos una imagen de su doble función: la de recortar las conductas sociales al tiempo que promociona las consignas de libertad y justicia. El ejercicio de este ocultamiento, siguiendo a Ricardo Entelman (1982) y Enrique Marí (2009) es el ejercicio de un poder sobre el deseo. El psicoanálisis encuentra el poder donde éste se fusiona con el deseo. En palabra de Entelman (1982), el psicoanálisis se propone explorar la represión burocrática del deseo, "desenganchando la explicación de las conductas sociales de los ocultamientos estructurados por el discurso" (18).

El cuerpo de leyes que enuncian la regulación de las relaciones entre los hombres, comparable a plexo legal de la lengua que regula al hombre que, al hablarla, la preserva, ha ocultado la producción de un sujeto subordinado mediante

2. En Obrar mal, decir la verdad, Foucault reconoce los programas de control que interpelan a un sujeto para que los haga suyos. La sujeción no se produce sin la condición dada de la ceguera de quien es sujetado. En palabras de Fabienne Brion y Bernard Harcourt (2014), que parafrasean la premisa arendtiana, "es nuestra docilidad que hace del mal una banalidad" (301). 
la estrategia de anunciar un individuo soberano. El interés de la crítica jurídica que asumimos aquí reside en que permite distinguir no sólo el sujeto construido en el discurso sino también de la especificidad de su racionalidad emergente. Como hemos explicitado en otros trabajos (ANICETO, 2018; ANICETO, 2017), la ficción del derecho como la representación de la ley encarnada en el sujeto que pronuncia una sentencia es un efecto estructural de las instituciones.

Con esto, abandonar la idea de un vínculo transparente entre el sujeto hablante y la significación exige abandonar la premisa que sostiene que las instituciones conforman un cuerpo inmutable que habla. Es esta antigua premisa la que habilita todo un cuerpo de categorías de análisis del discurso, principalmente azuzadas por el psicoanálisis de las instituciones y la antropología (FOUCAULT, 1969). Pierre Legendre $(1982 ; 1974)$ avanza sobre el ámbito crítico del discurso institucional en base a agudos análisis de conceptos elaborados por la teoría psicoanalítica. El autor declara el propósito final de su producción: "trabajar para descubrir el modo operatorio común de toda censura" (LEGENDRE, 1974, p. 14). Esto es, aún el sujeto autorizado a emprender la lectura de la sentencia en un juicio dice un discurso otro, distinto del enunciado que pronuncia el individuo que lo encarna circunstancialmente en la audiencia judicial. Aquello que Enrique Kozicki (1982) llama la "docta manipulación de las creencias" por el discurso, no es asignable desde una perspectiva asentada en la noción del sujeto hablante, libre y guardián de la tradición que transmite. Estudiar el orden dogmático de la censura exige reconocer el sujeto construido por ese orden. La creencia construida por las epistemes de las disciplinas, como la jurídica, consiste, en este sentido, en el mito fundador de la encarnación de la ley (LEGENDRE, 1974) que establece las condiciones de posibilidad del gobierno por la verdad y de la obligación de verdad del sujeto de discurso.

Lo dicho hasta el momento se propone concluir que naturaleza del concepto posición enunciativa no sólo aleja el planteamiento arqueológico de Foucault (1969) de la perspectiva antropológica del sujeto, sino que presenta una categoría capaz de analizar los discursos con asiento en nociones distintas a las impuestas por los mismos procedimientos coercitivos que los limitan.

En respuesta a las críticas que lo identifican con los principios de la tradición estructuralista, Foucault (1969) asume una postura severa: "lo que tanto se llora es la desaparición de esa forma de historia que estaba referida en secreto, pero por entero, a la actividad sintética del sujeto (...) lo que se llora es la posibilidad de reanimar por el proyecto, el trabajo del sentido" (FOUCAULT, 1969, p. 23). 


\subsection{El significante como la ley y su aplicación}

Uno de los términos de la relación, recordemos, es ocultado. El término al que Foucault se refiere, si cabe alguna duda, es el del origen del sentido frente al significante que no hace más que solidarizarse con él y ofrecerse como su lugar de paso. Precisamente es este acto de elisión el que organiza los elementos de la superficie de emergencia del acontecimiento discursivo. Sin embargo, es a la vez el que otorga al significante el papel privilegiado de mediación necesaria para el acceso al significado, un transmisor fiel e incontestable. El compromiso por desterrar finalmente la soberanía del significante cobraría, entonces, un objetivo definido: iniciar el trabajo de restituir al discurso su dimensión positiva sin olvidar sus condiciones negativas de aparición, los actos de corte y control que actúan sobre los umbrales de su irrupción.

Esta ha sido, según Foucault (1969), una dimensión histórica e institucionalmente ocultada. Historizar las instituciones y su operación de clausura implicará historizar no sólo sus restricciones sino el aspecto al que pretendemos hacer referencia aquí: los discursos emergidos como una afirmación al interior del sistema de negación y escansión. Al decir positividad emergida, decimos prácticas efectivas no-previstas por la doctrina, que ésta no toma a cargo, pero que, sin embargo, no puede expulsar fuera del dominio que intenta controlar.

Paradójicamente, la soberanía del significante coloca al documento a restituir el pasado del cual emana el sentido original, a pesar del significante mismo. Este razonamiento cumple con una función abstractiva que elide la realidad del acontecimiento discursivo.

Los reparos de Foucault en la HGr parecen dar muestras de una preocupación por explorar en las condiciones de posibilidad de una ciencia histórica no causal, que remueva las estructuras fijas y las reglas de unidad contractivas (como las duplas significante-significado u origen-regularidad) y que ponga en cuestión el punto de vista que acepta la relación de necesidad entre los sistemas restrictivos y la contingencia de un discurso. En el ejido del gobierno por la verdad jurídica al que nuestro autor hace referencia en Obrar mal, decir la verdad, el significante no ilustra un producto del hablante que mantiene la lengua, ni la materia que restituye el fundamento, sino una ley y su aplicación al mismo tiempo, una huella de las luchas que aporta a ocultar. 


\subsection{La disciplina}

Entre los procedimientos de control del discurso emergente también figura la disciplina como acción de delimitación del lugar del acontecimiento, los márgenes de su azar, las condiciones de su aparición. La dimensión contingente de la práctica discursiva no supone la emergencia de discursos libres de control, sino el funcionamiento de enunciados que irrumpen subordinados y controlados por procedimientos coercitivos. Los designios de una determinada voluntad de verdad son ejercidos, dirá el propio Foucault (1975) tiempo después de la primera edición de La arqueología del saber, a través de una tecnología disciplinar operante en los discursos. Materia prima de los cortes y escansiones ejercidos sobre la masa abundante de discursos por decir. Sin embargo, de entre los resquicios dejados por el acto negativo del corte y la exclusión, emerge la práctica positiva, performativa del discurso.

En el caso del interdiscurso judicial, la positividad del discurso emerge en instancias en las que un formidable instrumental simbólico, el formalismo iterativo del ritual, pone en escena la normatividad jurídica y la ley, haciéndolas existir (KOZICKI, 2004). Las audiencias judiciales son lugares ritualmente investidos por la ley que, según Pierre Legendre (1982), se configuran en una escena pública autorizada por el derecho, donde se despliega una particular dramatización de las reglas de la doctrina.

El reconocimiento del carácter performativo de la práctica discursiva se nos presenta, por lo tanto, como un requisito para comprender: 1- la diferencia introducida por un enunciado en un campo discursivo tanto con prescripciones verbalizadas como con lo que Enrique Marí (1982) llama códigos no-dichos, y 2- el discurso jurídico como fijeza dramatizada ${ }^{3}$ en cada práctica enunciativa del ritual judicial. La especificidad de las gramáticas jurídicas consagra la práctica discursiva a un dominio que hace explícitas las restricciones y aparentemente no deja lugar a la contingencia y la diferencia. Sin embargo, tanto las conclusiones de la sociología del derecho que sostiene la teoría del pluralismo jurídico (CÁRCOVA, 2009; DE SOUSA SANTOS, 2009), como la tradición postestructuralista (FOUCAULT, 2014; MARÍ, 1993) anuncian una hermenéutica crítica del discurso jurídico. Con esto, reconocemos que, como afirma Schechner (1990), "todo puede ser estudiado como performance (...), como una conducta que forma parte de ceremonias rituales más formales" (115). Sin embargo, diremos que la noción arqueológica foucaultiana de disciplina resiste al análisis con pretensión de reproducir la empresa de síntesis y unificación. La regularidad del conjunto de performances de los diversos espacios

3. En alusión a la practiced fixity de Richard Schechner (1993). 
discursivos, incluido el jurídico, y las limitaciones a que son sometidos, deben ser asignadas con una mirada que reconozca el carácter dinámico de la dramatización verbal.

Es este uno de los puntos en los cuales descansa la crítica de Dreyfus y Rabinow (1982) a la arqueología foucaultiana:

se podría sospechar que Foucault advierte que las prácticas discursivas (...) tienen el poder de formar objetos y sujetos. Sin embargo, parece claro que las regularidades que describe no son simples ordenamientos accidentales que pueden ser leídos desde la superficie del discurso (112).

Al sacar las consecuencias de esta observación, ruge el interrogante sobre un anticipo del mismo Foucault (1969): "si se aísla la instancia del acontecimiento enunciativo, no es para diseminar una polvareda de hechos. Es para estar seguro de no referirla a operadores de síntesis que sean puramente psicológicos" (46). El autor de La arqueología del saber intenta convencernos de que las reglas características de la práctica discursiva operan limitando la emergencia azarosa y la abundancia de objetos y conceptos a favor de una determinada voluntad de verdad. La regularidad no se encuentra albergada en una entidad psíquica que opone y contrae un significado y un significante, ni apoyada sobre actos de repetición compulsiva o de una dispersión total que pueda conjurar todas las limitaciones. La regularidad debe ser asignada sobre la realidad misma del discurso, positiva en su misma emergencia pero negativa por su histórica sumisión a un sistema de control y limitación.

Por caso, la negatividad de los mecanismos que operan en la superficie de emergencia del discurso judicial se constituye en un espacio relacional de las interacciones entre diversos enunciados. La realidad del espacio discursivo donde emergen posicionamientos en disputa por la construcción narrativa de la resolución justa, se configura en la competencia entre opciones estratégicas adversativas. Lo real que la arqueología foucaultiana apuesta por retener es asignable a las luchas que deben reconocerse sobre todo campo discursivo emergente. Entendemos campo discursivo, como lo hace Maingueneau (en CHARAUDEAU y MAINGUENEAU, 2002). Como un conjunto de formaciones discursivas (FD) (FOUCAULT, 1969) coexistentes e interactuantes que entran en relación de competencia, delimitándose recíprocamente. No tardaría, el autor del proyecto arqueológico, en poner en palabras una definición de este espesor para la práctica discursiva jurídica, como juego estratégico y polémico que compone un "conjunto regular de hechos lingüísticos en determinado nivel, y polémicos y estratégicos en otro" (FOUCAULT, 1978, p. 15). 
Los discursos emergen limitados por una disciplina, por lo tanto, en la medida en que ésta impone en cada enunciado un juego de reactualización de relaciones entre objetos, conceptos, modalidades de enunciación y elecciones teóricas.

\subsection{Dreyfus y Rabinow sobre el sujeto y la posición del arqueólogo}

Las objeciones de Dreyfus y Rabinow (1982) a la noción posición enunciativa merecen, a nuestro entender, una revisión.

A la afirmación de que "la descripción del archivo despliega sus posibilidades a partir de los discursos que acaban de cesar precisamente de ser los nuestros" (FOUCAULT, 1969, p. 222) los críticos responden sin vacilar que "el resultado es una especie de nihilismo que enfatiza el papel de la interpretación" (DREYFUS y RABINOW, 1982, p. 115). Argumentan que "el arqueólogo debe provocar una 'escisión del yo' con el propósito de observar, como un espectador distanciado, los muchos fenómenos en los cuales no puede dejar de verse involucrado" (115).

El eje de sus críticas reside en postular que las prácticas discursivas configuran un espacio no-significativo, autogobernado por transformaciones en las cuales los enunciados, sujetos, objetos, conceptos y estrategias se toman como plenos de sentido para quienes participan de esas prácticas (DREYFUS y RABINOW, 1982).

Sin embargo, Foucault (1969) no declara al arqueólogo ubicado en el exterior de la práctica discursiva. Lo ubica, más bien, atento al régimen disciplinar que gobierna los modos de relación en el acontecimiento discursivo. De aquí se desprende que la función atribuida al arqueólogo de la HG sea recomponer tanto las evidencias del dominio de verdad que rige la emergencia de los discursos como las de su inserción en los designios de esa relación de poder. El análisis histórico procede, entonces, con un doble cuidado: el de recomponer evidencias y establecer las condiciones de posibilidad política para su debilitamiento.

La distancia que Foucault sugiere para aquel es la necesaria para objetivar el lazo que una disciplina dibuja entre un enunciado y el presunto sentido originario. Es en relación con la ceguera que traduce la aceptación de la soberanía de los orígenes que se vuelve necesaria la externalidad del arqueólogo. Las relaciones que condicionan la posibilidad del discurso "no definen su constitución interna, sino lo que le permite aparecer, yuxtaponerse a otros objetos, situarse en relación con ellos, en un campo de exterioridad" (FOUCAULT, 1969, p. 63) (el subrayado es mío).

En otras palabras, a la noción de descripción intrínseca que reconocemos en el proyecto arqueológico le corresponde asignar las funciones enunciativas que una práctica discursiva desempeña en el contexto de prácticas en el que irrumpe 
y establecer "la manera constante de relacionar todo un campo, no discursivo, de apropiación, de intereses y de deseos" (FOUCAULT, 1969, p. 92- 93).

\subsection{Un sistema de sumisión de sujetos y discursos}

Hemos relevado la definición foucaultiana de los procedimientos internos de limitación del discurso, consolidados en las figuras del autor y la disciplina ${ }^{4}$. Ahora bien, nuestro autor reconoce un tercer grupo de procedimientos, entre los cuales figura la doctrina. Es a través de ella, visible en la forma del ritual, que se establecen exigencias de acceso y calificación al discurso. Es ella la autora de una genealogía del sujeto que el trayecto intelectual de Foucault se esfuerza en describir.

Podemos decir, entonces, que el discurso ritual se articula en campos enunciativos donde se libran relaciones singulares, 1) funcionales a una voluntad de saber que autoriza ciertos enunciados y posiciones de sujeto, 2) reactualizadas por una disciplina que actúa limitando la posibilidad de otras relaciones en el orden doctrinario, y 3) singulares del carácter contingente del discurso, que obedece a su condición de acontecimiento.

Así, podemos afirmar aquí que sus postulados pre-metodológicos, que declaraban su renuncia a la búsqueda del sentido serio de los discursos, constituía, en el transcurso de su misma progresión, la génesis de una nueva seriedad: aquella que proponía un trabajo de introspección y reconocimiento del espacio donde que se instituye el juego de identidad de los discursos. Juego dispuesto por una determinada racionalidad práctica, con un repertorio complejo de objetos y conceptos que resultarán inabordables sin la introducción de nuevas nociones que permitan reconocerlos en lo que tienen de dispersos y discontinuos.

El proyecto arqueológico irrumpe en los revueltos finales de la década de los $60^{`}$ poniendo en el tapete un tema que generó polémica en años posteriores. La intención de describir las estructuras de la historia, de sus reglas relacionales, mostraba la posibilidad de acceder al efecto de ficción producido por las unidades formales de discurso, en tanto enunciados sujetados a una significación originaria. Toda vez que emerge, necesariamente, explorando sus propias condiciones de posibilidad, el proyecto arqueológico vuelve inevitable poner en cuestión la radicalidad de la ruptura producida por el mayo francés produce en el dominio de saber occidental sobre el hombre y sus reivindicaciones que afirma estar subvirtiendo.

4. En las próximas líneas, desarrollaremos una lectura del juego de identidades establecido por el comentario. 
La propuesta arqueológica es perfectamente armonizable con la genealógica, en el sentido de que denuncia la elisión del discurso en tanto acontecimiento de una relación de continuidad y ruptura simultánea con el sujeto originario.

Con todo, a la pregunta retórica de Foucault (1966, p. 50) "¿qué civilización, en apariencia, ha sido más respetuosa del discurso que la nuestra?" (FOUCAULT, 1966, p. 50), le corresponde una respuesta implícita que asignamos a la totalidad de su obra: la misma civilización que constituyó poderes y los ejerció por una tecnología disciplinar y resguardó la institución mediante el gobierno de los sujetos por la verdad.

\section{PROPUESTA DE FOUCAULT EN LOS UMBRALES}

La tradición estructuralista que La arqueología de saber insiste en diferenciar prudentemente de su planteamiento niega que los sujetos de habla sean capaces de modificar las reglas del sistema de la lengua y atribuye a la fuerza social de la tradición el papel de garante de la inmutabilidad de ese sistema en el tiempo. En uno de sus pasajes, el Curso de Linguiistica lo enuncia como una máxima: "en todo instante la solidaridad con el pasado pone en jaque a la libertad de elegir" (SAUSSURE, 1945, p. 100).

Todas las categorías reunidas por Foucault (1969) en torno a la idea de las regularidades enunciativas se reconocen capaces de abordar el nivel finito en el que se constituye la realidad del acontecimiento discursivo. Sus propuestas niegan las continuidades subyacentes y los estados flotantes poblados de pensamientos amorfos que esperan por tomar forma en significantes. Sin embargo, también niegan la irrupción de cambios importantes introducidos por discursos que digan sólo lo nunca dicho.

No dedica a la contingencia de la enunciación un papel de transformación que la desprenda completamente de lo que ha sido dicho e introduzca un escenario de novedad al margen del tiempo.

Esto nos dirige la mirada a una de las principales dimensiones de la propuesta de Foucault sobre formaciones discursivas: el estudio en los umbrales porosos y dinámicos donde emerge el comentario, entre el origen y la regularidad de los discursos, el estudio, en fin, de las temporalidades discursivas.

\subsection{El tiempo de la tradición vs las temporalidades discursivas}

Las reflexiones de Foucault (1969) sobre lo original y lo regular de los discursos contienen precisiones que las destacan de las estructuralistas. Un reparo en la categoría estructuralista del punto de vista representará el insumo para esta distinción. 
Trubetzkoy (1939), en sus postulados sobre las oposiciones fonológicas, asegura que "el punto de vista que se decide adoptar, del que depende la identidad con que aparece un objeto, es, como se ve, un punto de vista determinado por relaciones" (23). El punto de vista que crea el objeto del estudio semiológico, así, se encuentra contenido en el sistema de relaciones que le dan valor (Saussure 1945) a los signos de una lengua. El encuadramiento de este concepto dirige a una definición singular del tiempo: un sistema de relaciones permanece inmutable a través y a pesar de los usos. La tradición de la fuerza social (Saussure, p. 1945) es la que, a través del tiempo, garantiza la pervivencia de las relaciones depositadas en el cerebro de los hablantes. El factor bistórico, como Saussure (1945) denomina al tiempo condensado en los estados de la lengua (ANICETO, 2013), excluye toda posibilidad de transformación y, así, "la historicidad del signo y su arbitrariedad son aspectos indisolubles" (SAZBÓN, 1976, p. 27).

El repertorio de nociones que ubica al tiempo en el lugar que garantiza lo estático del sistema es cuestionado desde otro que es posible identificar emplazado en las propias coordenadas temporales construidas en la práctica discursiva.

La arqueología describe un plano de homogeneidad enunciativa que tiene su propio corte temporal. En esas unidades tan confusas a las que llaman 'épocas', hace surgir, con su especificidad, 'períodos enunciativos' que se articulan, pero sin confundirse con ellas, sobre el tiempo de los conceptos, sobre las fases teóricas, sobre los estadios de formalización y sobre las etapas de la evolución lingüística (FOUCAULT, 1969, p. 194).

Lo temporal, en el complejo teórico foucaultiano, se constituye disperso en discontinuidades y rupturas, organizado en períodos enunciativos, asistiendo a la actividad positiva de aparición de prácticas discursivas y, simultáneamente, a la negativa de su rarefacción.

\subsection{Unidades tradicionales como tipos institucionalizados}

Vemos la manera en que Foucault pone a prueba las relaciones que el estructuralismo había opacado: lo serio y la voluntad de verdad, lo teórico y la tecnología disciplinar que lo aplica, los límites que determinan la aparición de un discurso y la separación o exclusión de otros.

En fin, las unidades discursivas arbitrarias y su estabilidad inmutable aparecen cristalizando un vínculo solidario con el pasado de la tradición, motivado desde una razón práctica, menos voluntaria que coercitiva. Así, al discernir sobre qué unidades asignar en un conjunto discursivo de una época dada, estaremos debatiendo sobre las posibilidades de limitar el alcance de unos específicos efectos de control. 
Michel De Certeau (1978) alude con énfasis al fenómeno de aislamiento de unidades irreflexivas por parte de la historia tradicional. El autor identifica una suerte de tecnología disciplinar moderna al servicio de la imposición de esos límites y la necesidad de reconocer nuevas unidades.

\begin{abstract}
"Ciertamente, la constitución de series, el aislamiento de 'coyunturas' globales, como también las técnicas de la novela o del cine (...) han permitido el establecimiento de cuatros sincrónicos y renovado los medios tradicionales que hacen actual entre ellos momentos diferentes. Esto no obsta para que toda la historiografía nos plantee un tiempo de las cosas como el contrapunto y la condición de un tiempo discursivo" (DE CERTEAU, 1978, p. 104).
\end{abstract}

\title{
2.3. El origen y lo regular
}

La reflexión de Foucault sobre el deber que los orígenes le imponen al discurso regular, se dirige, asimismo, a afirmar la existencia de rupturas (no reconocidas) de esa fidelidad con lo dicho. El juego del comentario opera, por lo tanto, una actividad de exclusión. El azar, lo que podría decirse, es conjurado por la disciplina que crea para el comentario la máscara de la repetición. Foucault propone desentrañar esa operación mediante la advertencia sobre la positividad de los elementos construidos en la práctica discursiva. En la realidad del discurso, en su ocurrencia y efectividad, es donde reside el elemento transformador que resiste a la coacción de lo ya dicho. En palabras del autor, "lo nuevo no está en lo que se dice, sino en el acontecimiento de su retorno" (FOUCAULT, 1966, p. 29).

Considerando particularmente el par de términos origen coactivo - práctica discursiva contingente, es reconocible que la objeción hecha por Foucault a la Historia de las Ideas señala la anulación históricamente posibilitada del segundo. Recordándonos el carácter oculto de las operaciones de la tecnología disciplinar, nuestro autor advierte que esta eliminación "no puede ser más que un juego, una utopía, una angustia" (FOUCAULT, 1966, p. 27).

Buscar en el gran amontonamiento de lo ya dicho el texto que se asemeja "por adelantado" a un texto ulterior, escudriñar para descubrir, a través de la historia, el juego de las anticipaciones o de los ecos, son entretenimientos simpáticos, pero tardíos de historiadores de pantalón corto (FOUCAULT, 1969, p. 187-188).

Si un discurso renace en cada repetición partiendo de sentimientos, pensamientos sujetos a la tradición, bastaría con volver del discurso a ellos para descifrar la verdad de un referente explícito, fechado, pero sobre todo, comentado por una compulsión a la repetición. 
Mientras la perspectiva estructuralista se empeña en graficar los límites imborrables entre lo original y la contingencia, y en otorgar primacía al sistema de la lengua por sobre los efectos ruinosos de los cambios introducidos por los usos (SAUSSURE, 1945), la descripción arqueológica propone hacer visible ese juego al nivel de los discursos e interceptar la voluntad de verdad que promueve. Antes que lo nuevo y lo viejo, Foucault se esfuerza en diferenciar la contingencia de la práctica discursiva que "permite decir otra cosa aparte del texto mismo (...)" (FOUCAULT, 1966, p. 29).

Con todo, "no se puede admitir una diferencia de naturaleza entre enunciados creadores y enunciados imitativos (...). El campo de los enunciados es un dominio activo, de cabo a rabo" (FOUCAULT, 1969, p. 189).

El ocultamiento de las reglas de tales juegos, declaradas por disciplinas como la lingüística, la fonología, la lógica, etc., como inmutables e inaccesibles para el hablante, es delatado por Foucault en $A S$, como la condición de emergencia de los discursos.

Es posible identificar el núcleo de las reflexiones de Foucault en torno a los discursos en una afirmación implícita: los procedimientos de exclusión y control que operan en los umbrales de aparición de los discursos, a su vez, como tipos institucionales, proveen de las herramientas metodológicas que ban permitido analizar los enunciados ocultando esos procedimientos y sus efectos.

La $H G$ procede, entonces, en un doble enmascaramiento. Esforzada en el objetivo de ocultar su temor por la discontinuidad, la abundancia dispersa y lo peligroso que puede habitar en los discursos (FOUCAULT, 1966), ocultan también los procedimientos de expulsión y control a través de los cuales los restringen y el juego de continuidad e identidad uniforme que imponen en su lugar. "Al descentramiento operado por la genealogía nietzscheana, opuso la búsqueda de un fundamento originario" (FOUCAULT, 1969, p. 25).

\subsubsection{La policía discursiva y la rarefacción de lo positivo}

Como dijimos, Foucault concibe la práctica discursiva como emergente sobre un campo en el que las formaciones discursivas son enrarecidas y en que un sistema de exclusión y control limita su abundancia y su azar. Sin embargo, la práctica discursiva es, en sus palabras, una actividad positiva. El doble carácter del discurso, el de su positividad formada según reglas que se imponen por un sistema con procedimientos negativos, es caracterizado por Foucault al afirmar que "todo el campo enunciativo es a la vez regular (en su condición limitada por el juego de identidad de la repetición) y se halla en estado de alerta (en relación con la dispersión 
de objetos, conceptos, modalidades de sujeto y estrategias)" (FOUCAULT, 1969, p. 191) (las aclaraciones son mías).

Un fragmento del debate con Chomsky resulta clarificador para comprender esto a la luz de sus postulados más generales:

Es una costumbre considerar (...) que el poder está en manos del gobierno (...) como la administración, la policía, el ejército y el aparato del Estado (...).Pero creo que el poder político también se ejerce a través de la mediación de ciertas instituciones que parecerían no tener nada en común con el poder político (FOUCAULT en CHOMSKY y FOUCAULT, 1974, p. 23)

Las instituciones a que hace referencia son portadoras de un poder de policía sobre los discursos. La noción saussureana de institución humana e institución pura del lenguaje a que hicimos referencia nos permite captar, por oposición, la dimensión de la función de control que le asigna a estas instituciones, distintas, en un sentido, a las instituciones administrativas del Estado.

La institución humana del lenguaje, en la perspectiva estructuralista, garantiza la inmutabilidad del sistema a lo largo de sus sucesivos estados. Lo que el autor considera en relación con las instituciones es, en primer lugar, su estatuto independiente del lenguaje. Los efectos de la coacción institucional impuesta sobre la realidad del discurso no son identificables con instituciones que preceden a su aparición, sino en una especial configuración relacional producida en la exterioridad de sus vecindades.

La noción de institución, en segundo lugar, es asignada de una cuota de poder diferencial en relación con la designada por el estructuralismo en la institución pura. El lenguaje, como institución bumana, posibilita la supervivencia de un sistema primigenio de reglas a través de la acción de una masa hablante encargada de transmitirlo en el tiempo. El poder de la tradición, así, como el poder de la inercia. Foucault favorece una idea de un sistema históricamente constituido, modificable e institucionalmente coactivo. El poder no reside en el tiempo en que la tradición de una masa ininteligente lo reproduce y lo resguarda, sino que estriba en la actividad agresiva de un corte, en mecanismos de enrarecimiento que instauran el juego de identidades del discurso como repetición, como individual y re actualizador de las reglas del sistema.

Siguiendo a Foucault (1966, 1969), afirmamos que este juego obedece a un profundo temor a la masa de cosas dichas, a la utopía de un pacto originario que esquive la peligrosa y monstruosa materialidad del discurso. El poder institucional, como es caracterizado por el autor, no es ejercido avivando la permanencia de los elementos de un sistema, sino transformándolos, expulsando una población 
indefinida de ellos al exterior monstruoso y enrareciendo los discursos que aparecen como válidos. Podremos afirmar: el poder, históricamente instituido e impuesto es el que configuró el artificio de la identidad inmutable, a-histórica de la lengua. En fin, no es una institución humana, sino la institución de una policía discursiva la que actúa limitando, excluyendo, desautorizando, y sometiendo discursos a sujetos y sujetos a discursos.

En un primer cuestionamiento, los autores de la crítica hacen referencia a la tenue frontera que el método arqueológico establece entre lo negativo del sistema de control y lo positividad del acontecimiento discursivo. Consideran que "se podría esperar distinguir entre la regla de aparición y la ley de exclusión o entre las leyes que gobiernan las entidades mentales" (DREYFUS y RABINOW, 1982, p. 188). La esperanza de llegar a distinguir taxativamente los límites de las leyes de exclusión o de entidades mentales contradice en dos puntos, al menos, la perspectiva que Foucault adopta para tratar los acontecimientos discursivos. En ese marco, asume que las leyes de exclusión actúan mediante sistemas negativos, limitando la abundancia y la proliferación inagotable de discursos. No existe, en este punto, la posibilidad de pensar en reglas de aparición como aquellas que dictaminan la fecundidad ilimitada de los discursos y que terminan anuladas por la imposición de las reglas negativas de rarefacción.

La segunda crítica que articulan, se anticipa a asegurar que, ya que Foucault afirma que "las reglas no están en la mente de aquellos cuya conducta describen (...) se podría suponer, entonces, que dado que no hay reglas subjetivas que seguir, debe tratarse de reglas que sirven para sistematizar los fenómenos (...)" (DREYFUS y RABINOW, 1982, p. 109). Esta objeción pone sobre el tapete un tema que podemos nombrar como el del origen o de la fuente de las reglas. Una conclusión apoyada en la inferencia de Dreyfus y Rabinow aseguraría que las únicas instancias posibles de establecimiento de la regla tendrían lugar antes del fenómeno -en la mente del hablante- o en una operación metodológica ulterior que intervendría para re codificarla y asignarle coberencia a los enunciados. Sin embargo, con esto, estaría aportando seriedad a lo que Foucault define como el juego o la utopía de la reactualización permanente de las reglas. Reglas que el autor no designa al servicio de la coberencia de los enunciados, sino para explicar la regularidad de la dispersión de sus elementos.

En tercer término, los autores niegan que el método arqueológico sea el planteo de categorías alternativas a la lógica de la causalidad. Estiman que, por el contrario, las reglas, como las define el autor de AS, "tendrían, presumiblemente, tan sólo un valor descriptivo, y sin embargo Foucault, les atribuye su propia 
eficacia causal. Las reglas, según parece, actúan sobre los fenómenos" (DREYFUS y RABINOW, 1982, p. 109). A propósito de esto, no está de más recordar que cuando Foucault utiliza la expresión regla, está identificando tipos de relaciones reciprocas y de inter dependencia características de las prácticas discursivas. Las reglas de formación de los elementos del discurso cristalizan las relaciones que se entablan entre ellos, por lo tanto, no deberíamos ubicar su emergencia en una instancia previa al discurso sino en la de su realidad efectiva (en un baz dinámico de relaciones). No se constituyen, como vemos, en la causa de los discursos, sino en aquello que permite describir la exterioridad de su acontecimiento. Foucault (1969) se expresa críticamente sobre el hábito que le atribuye a la historia de las ideas de establecer el sistema de causalidad y de progresión de una razón trascendental que presenta un fenómeno como la causa de todos los que, compulsivamente, repetirán su esencia. Con esto, sugiere que lo prescriptivo de las reglas no actúa amarrando distintos estados sucesivos y repetitivos a un origen coactivo, sino determinando, sobre un campo enunciativo, las formas de coexistencias. Las reglas no explican las causas, sino las relaciones.

\section{LA POSITIVIDAD, EL COMENTARIO Y LA PERFORMATIVIDAD DEL DISCURSO}

Arribamos a este punto de la reflexión, abordando la propuesta de Foucault, alumbrada, en parte, por su voluntad de desprendimiento de temáticas y métodos que le siguen imputando. Foucault, ya lo dijimos, mantiene en vilo su preocupación por evidenciar la operación de procedimientos de sumisión impuestos desde una racionalidad institucional. Pero sobre todo, ensaya un principio de método que no ha dejado de iluminar, aunque así tienda a asumirse, el carácter histórico, institucional de la coerción ejercida en la formación de esas estructuras. Los objetos, conceptos, modalidades enunciativas y elecciones estratégicas no representan espectros en un haz metafísico de relaciones. Constituyen, antes bien, las categorías analíticas útiles a reconocer la realidad que el estructuralismo sistémico ha elidido del discurso. Foucault denuncia la eliminación de la realidad singular del discurso por parte de la historia tradicional y recupera la dimensión del enunciado que ocurre librando un dominio de objetos y conceptos, autorizando a determinados sujetos y subordinando unos a otros por medio del juego de la doctrina.

Podremos establecer la regularidad de campos enunciativos y determinar las funciones que despliegan en el contexto de prácticas en la medida en que reconozcamos que las relaciones entre los elementos del discurso bacen, irrumpen como acontecimientos. 
Uno de los campos enunciativos donde es posible aplicar este enfoque es uno de los que llamó la atención de Foucault (2014) en el último tramo de su trayecto: la práctica discursiva judicial del acusado. Ésta emerge enrarecida por procedimientos externos e internos institucionales, pero positiva, regular y contingente. Rareza, en fin, de la positividad restringida, a la que es posible asignar objetos, conceptos, posicionamientos y estrategias, como hemos demostrado en otra ocasión (ANICETO, 2014).

Los acontecimientos de emergencia de formaciones discursivas en la escena judicial es denominada por Foucault (2014) durante sus clases en Lovaina los procedimientos de veridicción de la justicia. A pesar del énfasis en la ceguera de los sujetos como condición para vincularse a la obligación de verdad jurídica, es decir, a pesar del relieve otorgado a los procesos de subjetivación desde una perspectiva ética, no deja de ser concebido el problema político de la actuación del poder. La inclusión de la palabra del acusado en la historia del derecho, objeto de sus clases, no olvidan la categoría de origen que ciertos regímenes de gobierno imprimen sobre las relaciones que emergen, contingentes, sobre el rito de un juicio. Y eses, claro está, es un sustrato que debemos remontar al proyecto arqueológico que proponía pensar las regularidades y homogeneidades a través de las diferencias y las escansiones; o en otras palabras la aparente contradicción entre origen y regularidad.

Las performances enunciativas de un acusado emergen en un espacio dominado por un jeux de la verite jurídica que, simultánea y sucesivamente, administra otras tantas escenas rituales de diverso tipo. Definen, aíslan, y dan a la emergencia del objeto crimen, delimitándolo en las figuras posibles de lo criminal. Con Ingedore Koch (2001; KOCH y MARCUSCHI, 1998), asumimos que la construcción de objetos de discurso se produce en sistemas en los que se separan, se oponen, se re agrupan, se clasifican y se hacen derivar unos de otros.

Volviendo al ejemplo de la escena judicial, el enunciador autorizado por el conjunto discursivo doctrinal (el Pontífice autorizado por el Gran Otro, en términos de Legendre) impone sus delimitaciones a los enunciados emergentes en el contexto del rito institucional, pero no puede orientar las estrategias asumidas por cada performance, en un contexto en el que todos parecen estar representando un montaje institucional. La verdad delimitada por el Juez puede ser opuesta por la de un acusado, en la cual la posición enunciativa sea la de enunciador damnificado demandando reparación y atribuyendo responsabilidades.

Maingueneau (en CHARAUDEAU y MAINGUENEAU, 2002) brinda una lectura sobre la formación discursiva que confiere mayor sistematicidad al análisis de los campos discursivos donde intentamos reconocer programas de control, 
como el caso menos solapado del campo discursivo judicial. Como dijimos más arriba, Maingueneau toma la noción de campo enunciativo del proyecto arqueológico y la de campo del planteamiento bourdieuano y asume que es posible reconocer, en el discurso social, campos discursivos organizados en espacios discursivos que, a su vez, son compuestos y re compuestos por posicionamientos en pugna. Los espacios discursivos, "subconjuntos constituidos por al menos dos posicionamientos discursivos" (MAINGUENEAU en CHARAUDEAU y MAINGUENEAU, 2002, p. 81), son, entonces, constitutivamente agonísticos. La manifestación de una incompatibilidad entre posicionamientos en competencia replica las tensiones que están en la base misma de la FD.

\section{CONSIDERACIONES FINALES}

Desde una teoría crítica del discurso, consideramos que, en los espacios discursivos, las operaciones de categorización de objetos y las relaciones polémicas entre posicionamientos confrontados por sus estrategias, representan la lucha por la construcción de un dominio de validez doctrinal y de autorización.

Para la articulación de una perspectiva ética y política que conduzca a un abordaje estratégico de los campos discursivos, es necesario observar que la arena de lucha en que se constituye el discurso, es también la arena de competición entre discursos que, al tiempo que dicen la doctrina, compiten por el predominio de una verdad y un saber específico, avanzando sobre el espacio de lo no dicho. Desde la arqueología que define la regla característica de la práctica discursiva, pasando por la genealogía del poder de control jurídico y en su arribo a la perspectiva ética de las liturgias de verdad, Foucault elabora un programa cuya principal función es oponer la sujeción al poder mediante una descripción de las formas posibles de su desasimiento. El pasaje que el trayecto intelectual de Foucault anima es uno político y ético, del gobierno por la verdad jurídica al coraje de la verdad estratégica.

\section{REFERENCIAS}

ANICETO, P. D. (2018). La práctica jurídica como el evento de su dramatización: la miseen-scène del campo judicial, Foro, Revista de Ciencias Jurídicas y Sociales. Nueva época, v. 20, $n^{0} 1$, pp. 219-238.

ANICETO, P. D. (2017). Una reflexión sobre el carácter agonístico de la práctica de jurisdicción. La construcción de ámbitos de justicia en la liturgia que formaliza un combate. Nómadas. Critical Journal of Social and Juridical Sciences, v. 52, $n^{\circ} 4$, pp. 43-59. 
ANICETO, P. D. (2014). Las últimas palabras de Rafael Videla en el contexto del ritual judicial en Córdoba. Emergencias y articulación de objetos de discurso. GT 22 "Políticas y lugares de la memoria: acontecimientos, saberes, testimonios e instituciones (1955-2010). Actas del XI Congreso Argentino de Antropología Social, Facultad de Humanidades y Artes de la Universidad Nacional de Rosario.

ANICETO, P. D. (2013). El factor histórico de la lengua y el tiempo de los discursos. Forma y Función. v. 26, nº 2, pp. 11-40.

AUSTIN, J. L. (1962). Cómo bacer cosas con palabras. $3^{\text {a }}$ ed. Trad. Barcelona: Paidós, 1982.

AUSTIN, J. L. (1975). Emisiones realizativas. In: Vadés Villanueva, L. M. (ed.), La búsqueda del significado, $3^{a}$ Ed., Trad. Alfonso García Suárez. Madrid: Tecnos, 2000, pp. 419434 .

BRION, F. y HARCOURT, B. (2014). Situación del curso. In: Foucault, M. Obrar mal, decir la verdad. La función de la confesión en la justicia. Trad. Horacio Pons. Buenos Aires: Siglo XXI, 2014, pp. 281-340.

CÁRCOVA, C. M. (2009). Notas acerca de la teoría crítica del derecho. In: Courtis, Ch. (ed.). Desde otra mirada. Textos de teoría crítica del derecho. Buenos Aires: Eudeba, pp. 19-38.

CHARAUDEAU, P. y MAINGUENEAU, D. (2002). Diccionario de análisis del discurso, $1^{\text {a }}$ Ed. Trad. Irene Agoff. Buenos Aires: Amorrortu editores, 2005.

CHOMSKY, N. y FOUCAULT, M. (1974). La naturaleza bumana. Justicia versus poder. El debate, $1^{\text {a }}$ Ed. Trad. Robert Harvey. Buenos Aires: Nueva Visión, 2001.

ENTELMAN, R. (1982). Introducción. En: Legendre, P. (ed.). Discurso Jurídico: perspectiva psicoanalítica y otros abordajes epistemológicos, $1^{\text {a }}$ Ed. Buenos Aires: Hachette, pp. 9-20.

FOUCAULT, M. (2014). Obrar mal, decir la verdad. La función de la confesión en la justicia, $1^{\mathrm{a}} \mathrm{Ed}$. Trad. Horacio Pons. Buenos Aires: Siglo XXI, 2014.

FOUCAULT, M. (1978). La verdad y las formas jurídicas, $5^{a}$ Ed. Trad. Enrique Lynch. Barcelona: Gedisa, 1980.

FOUCAULT, M. (1975). Vigilar y Castigar, $1^{a}$ Ed. Trad. Aurelio Garzón del Camino. Buenos Aires: Siglo XXI, 2002.

FOUCAULT, M. (1970). El orden del discurso, $1^{\mathrm{a}}$ Ed. Trad. Alberto Gónzalez Troyano. Buenos Aires: Fábula Tusquets, 2008. 
FOUCAULT, M. (1969). La arqueología del saber, 2ª Ed. Trad. Aurelio Garzón del Camino. Buenos Aires: Siglo XXI, 2011.

FOUCAULT, M. (1966). Las palabras y las cosas: Una arqueología de las ciencias bumanas, $3^{\mathrm{a}} \mathrm{Ed}$. Trad. Elsa Cecilia Frost. Buenos Aires: Siglo XXI, 2008.

KOCH, I. V. (2001). A referenciação como atividade cognitivo-discursiva e Interacional. Cadernos de estudos lingüísticos, UNICAMP. v. 41, n 1, pp. 75-89.

KOCH, I. V. y MARCUSCHI, L. A. (1998). Processos de referenciação na produção discursiva. DELTA: Documentação de Estudos em Lingüística Teórica e Aplicada. v. 14, nºspecial, pp. 169-190.

KOZICKI, E. (2004). Hamlet, el padre y la ley, $1^{\text {a }}$ Ed. Buenos Aires: Gorla.

LEGENDRE, P. (1974). El amor del censor: ensayo sobre el orden dogmático, $1^{\mathrm{a}}$ Ed. Trad. Marta Giacomino. Barcelona: Anagrama, 1979.

LEGENDRE, P. et al (1982). Discurso Jurídico: perspectiva psicoanalítica y otros abordajes epistemológicos, $1^{\text {a }}$ Ed. Buenos Aires: Hachette.

MARÍ, E. (1993). Las ficciones de legitimación en el derecho y la política: de la sociedad medieval a la sociedad contractual. Crítica Jurídica. Revista Latinoamericana de Política, Filosofía y Derecho. $n^{0}$ 13, pp. 161-183.

MARÍ, E. (1982). 'Moi, Pierre Riviere...' y el mito de la uniformidad semántica en las ciencias jurídicas y sociales. In: Legendre, P. et al. El discurso jurídico. Perspectiva psicoanalítica y otros abordajes epistemológicos, $1^{\text {a }}$ Ed. Buenos Aires: Hachette, pp. 53-82.

SAUSSURE, F. (1945). Curso de linguíistica general. Trad. Amado Alonso, 24 ${ }^{\mathrm{a}}$ Ed. Buenos Aires: Losada.

SAZBÓN, J. (1976). Saussure y los fundamentos de la lingüística, $1^{\text {a }}$ Ed. Buenos Aires: Centro Editor de América Latina.

SCHECHNER, R. (1993). The future of ritual: Writings on culture and performance, $1^{\text {a }}$ Ed. Londres/ Nueva York: Routledge.

SCHECHNER, R. (1994). Ritual and Performance. In: Ingold, T. (ed.), Companion Encyclopedia of Antbropology, $1^{\text {a }}$ Ed. Londres/Nueva York: Routledge, pp. 613-648. 
SCHECHNER, R. (1990). Performance. Teoría y prácticas interculturales, $1^{\text {a }}$ Ed. Trad. Marta Ana Diz. Buenos Aires: Secretaría de Extensión Universitaria y Bienestar Estudiantil, UBA, 2000.

TRUBETZKOY, N. (1939). Principios de fonología, $1^{\text {a }}$ Ed. Trad. Delia García Giordano. Madrid: Editorial Cincel, 1973.

Recebido: 06/05/2018

Aceito: 09/07/2018 